\title{
Mental Disorder or Untreated Pneumonia
}

\section{Rawhi Omar}

Department of Veterans Affairs, University of Louisville School of Medicine, USA

*Corresponding author: Rawhi Omar, Department of Veterans Affairs, University of Louisville School of Medicine, 800 Zorn Avenue (113), Louisville, KY 40206, USA, Tel: 1-5022165724; E-mail: raomar12@gmail.com

Received date: January 28, 2016; Accepted date: February 02, 2016; Published date: February 09, 2016

Copyright: (c) 2016 Omar R. This is an open-access article distributed under the terms of the Creative Commons Attribution License, which permits unrestricted use, distribution and reproduction in any medium, provided the original author and source are credited.

\section{Short Communication}

A classic autopsy case scenario that is encountered by pathologists in hospitals with overworked psychiatric wards or hospice care is an elderly patient who was admitted for mental status change reported by relatives or close encounters, given a quick diagnosis of some form of psychosis (paranoid schizophrenia; bipolar disease etc), hospitalized for days or weeks under treatment with neuroleptic drugs with little assessment of his or her physical health (cursory physical exams and few laboratory tests) until it is reported that "the patient mental status had deteriorated significantly and the patient one day was found dead by the attending nurse".

Not every one of such cases ends up with an autopsy but of those who do get an autopsy, the most frequent cause of death (more than $50 \%$ in the author's experience) is bronchopneumonia that is often bilateral or severe [1]. Neuropathological examination in most of those cases shows nothing more than hypoxic encephalopathy. Some of these patients are in their late fifties or sixties with a relatively substantial productivity time left if their lives could have been saved and "fixed" with the simple use of an "antibiotic" to treat their respiratory tract infection!

Elderly individuals, because of age or poor nutrition-related, less than optimal functioning of the immune system, are more susceptible to respiratory infections $[2,3]$. The latter may start as a simple cold or flu but if not properly cared for with supportive measures (often lacking in the case of the homeless or a resident of low-quality hospice or a patient in a poorly managed psychiatric ward) can quickly progress from a simple viral infection to a superimposed severe bacterial pneumonia. The destruction of lung parenchyma by the inflammatory process (pneumonia) may significantly impact the total lung capacity for air exchange which results in reduction of vital organ oxygenation or tissue hypoxia. Brain hypoxia (hypoxic encephalopathy) almost always manifests itself in transient or permanent mental status change which can easily mimic many psychotic disorders. It takes a good physician (literally!), who obtains a good medical history and performs a discerning physical examination and even runs a few general health-related laboratory tests, to arrive at the more accurate diagnosis of pneumonia that is easily treatable then with an antibiotic $[4,5]$.

In the current literature, pneumonia is one of the most frequently reported causes of death among mentally ill patients above 65 years of age with or without dementia who are being treated with antipsychotic medications. The mortality rate among such patients is $15-30 \%$ or 1.5-2 times higher than in the general age-matched population $[6,7]$. These statistics are based on documented (pre-mortem) diagnosis and likely to be much higher if the post-mortem discovered cases are added. A large research project is probably needed to look at this overlooked group of patients. Clinicians treating mentally ill patients are strongly advised to closely monitor those patients, particularly at the early phases of antipsychotic therapy and with high doses. If pneumonia-related signs and symptoms are identified, the withdrawal and or dose-adjustment of antipsychotic treatment should be considered.

Unfortunately, it is by far much easier for an overworked health care provider, especially in a public facility with limited resources, to take the "short cut" of conducting a psychiatric evaluation and declaring the case a mental disorder. Such a "working diagnosis" typically means no more physicals, labs tests or antibiotic treatment of a simmering pneumonia from which the only remaining exit is death!

\section{References}

1. Salive ME, Satterfield S, Ostfeld AM, Wallace RB, Havlik RJ, et al. (1993) Disability and cognitive impairment are risk factors for pneumonia related mortality in older adults. Public Health Reports 108: 314-322.

2. Advance report of final mortality statistics: monthly vital statistics report. Hyattsville, MD: National Center for Health Statistics (1987) DHHS Publication 87: 1120.

3. Nichol KL, Margolis KL, Wouremna J, and von Sternberg T. (1996) Effectiveness of the influenza vaccine in the elderly. Gerontology 42 : 274-279.

4. Yoshikawa TT and Norman DC (1995) Infection control in long-term care. Clin Ger Med 11: 467-480.

5. Centers for Disease Control and Prevention (CDC) (1997) Outbreaks of pneumococcal pneumonia among unvaccinated residents in chronic care facilities-Massachusetts, October 1995, Okla., February 1996, and Maryland, May-June 1996. MMWR 46: 60-62.

6. Trifiro G (2011) Antipsychotic Drug Use and Community-Acquired Pneumonia. Curr Infect Dis Rep 13: 262-268.

7. Van der Steen JT, Mehr DR, Kruse RL, Sherman AK, Madsen RW, et al. (2006) Predictors of mortality for lower respiratory infections in nursing home residents with dementia. J Clin Epidemiol. 59: 970-979. 